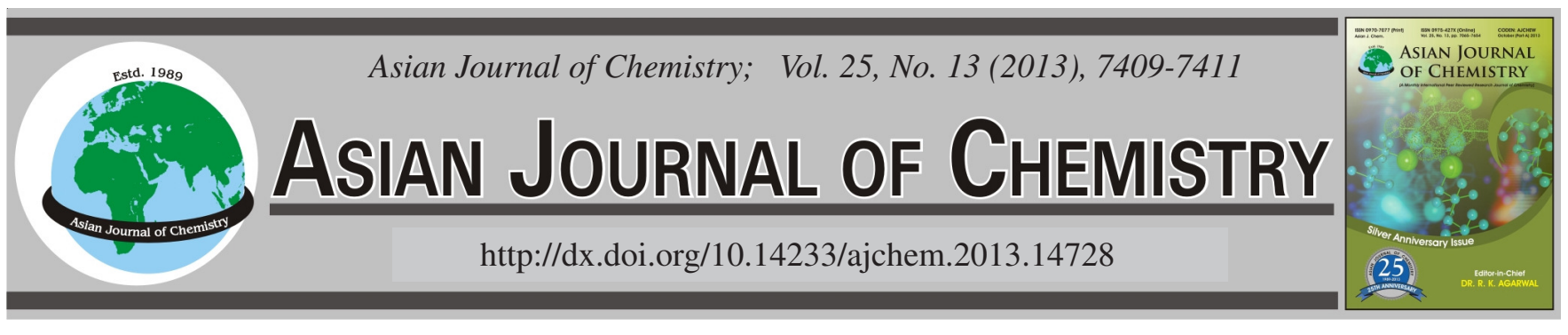

\title{
Synthesis of a New Reagent 1-(4-Antipyrine)-3-(3-nitroaniline)triazene and Its Colour Reaction with Mercury(II)
}

\author{
Chun-Shui Zhu* and Wenbin Chen
}

School of Chemical Engineering, Huaihai Institute of Technology, Liangyungang 222005, Jiangsu Province, P.R. China

*Corresponding author: E-mail: lygcwb11@163.com

\begin{abstract}
In this work, a new reagent 1-(4-antipyrine)-3-(3-nitroaniline)triazene and its colour reaction with $\mathrm{Hg}$ (II) was studied and a new spectrophotometric method for the determination of $\mathrm{Hg}$ (II) was established. The results showed that in the presence of micromulsion Tween-80, 1-(4-antipyrine)-3-(3-nitroaniline)triazene could reacted with $\mathrm{Hg}$ (II) to form a red stable complex of which the molar ratio of reagent:metal was 2:1 in $\mathrm{Na}_{2} \mathrm{~B}_{4} \mathrm{O}_{7}-\mathrm{NaOH}$ medium. The maximum absorption peak of the complex was located at $495 \mathrm{~nm}$ with the apparent molar absorption of $3.8 \times 10^{5} \mathrm{~L} \mathrm{~mol}^{-1} \mathrm{~cm}^{-1}$. Beer's law was obeyed in the range of $0.32-10 \mu \mathrm{g} / 10 \mathrm{~mL}$ for $\mathrm{Hg}(\mathrm{II})$ and the detection limit was 0.10 $\mathrm{mg} / \mathrm{L}$. Many ions did not interfere the colour reaction system due to the existence of ammonia. This method was applied to determination of $\mathrm{Hg}(\mathrm{II})$ in lead-zinc ore samples and the results were in accordance with those obtained by AAS method. Recovery was in the range of 103.0-103.2 \% and the RSD ( $=6)$ was not more than $4.6 \%$.
\end{abstract}

Key Words: Texmercapto-dextrangel, 1-(4-Antipyrine)-3-(3-nitroaniline)triazene, Spectrophometry, Mercury(II).

\section{INTRODUCTION}

Mercury is one of the main heavy metals hazardous to humans. All countries developed relevant standards about the mercury content present in the air, water and industrial wastewater emissions and the human intake of mercury, so it has important significance for both environmental protection and life science research to establish a method of rapid determination of mercury. Currently, methods of determining mercury(II) are variety, such as voltammetric method ${ }^{1}$, chromatographic method $^{2}$, inductively coupled plasma atomic emission spectrometric method ${ }^{3,4}$, cold vapor atomic absorption spectrometric method ${ }^{5}$, atomic fluorescence spectrometry method ${ }^{6}$ and spectrophotometric method, etc. Atomic absorption spectrophotometric method has highly sensitivity and selectivity, but it requires special and expensive instruments and devices. Its sensitivity rarely reaches $10^{-5}$ when spectrophotometric method uses pyridylazo ${ }^{7}$, porphyrin ${ }^{8}$, thiourea ${ }^{9}$ as reagent to determine mercury(II). Triazene reagent has a highly sensitivity of the colour reaction with the metal elements in IB, IIB group, especially there have been many studies and reports for determination of $\mathrm{Hg}^{2+}$ and the highest sensitivity of determination ${ }^{10}$ can reach $3.3 \times 10^{-5}$. But such reagents have poor selectivity and stability which leads to its application is limited. To further investigate the analytical performance of these reagents, this paper synthesized a readily available, synthesize easily a new reagent 1-(4-antipyrine)-3-(3-nitroaniline)triazene (ANTA) as well as a systematic study of its colour condition in determination of mercury(II) was conducted. In addition, the system used sulfhydryl dextran gel (SDG) to separate coexist ions in samples and concentrate mercury(II) and determined in the borax-sodium hydroxide buffer solution, Tween- 80 medium, it further improved the selectivity and sensitivity of this method and it is one of the highly sensitive systems in the determination of mercury. This method was used to determine trace mercury(II) in lead-zinc ore samples and the results were in accordance with those obtained by the cold vapor atomic absorption spectrometry results.

\section{EXPERIMENTAL}

UNICO WFJ 7200 spectrophotometer (Shanghai Analytical Instrument Factory V); $\mathrm{pH}-3 \mathrm{C} \mathrm{pH}$ meter (Shanghai Precision kore Magnetic Co., Ltd.). $1.0 \mathrm{mg} \mathrm{mL}^{-1} \mathrm{Hg}$ (II) standard stock solution: weighed $0.1000 \mathrm{~g}$ metallic mercury, lay in the 250 $\mathrm{mL}$ beaker, added the nitric acid, installed it into the hood slowly and heating to break down, cooling, moved it into 1000 $\mathrm{mL}$ volumetric flask, diluted to the mark with distilled water, shake, before using this solution, it was diluted to standard working solution of $10 \mu \mathrm{g} / \mathrm{L}$. Borax- $\mathrm{NaOH}\left(\mathrm{Na}_{2} \mathrm{~B}_{4} \mathrm{O}_{7}-\mathrm{NaOH}\right)$ buffer solution: $\mathrm{pH} 10.2,0.05 \mathrm{~mol} / \mathrm{L}$ of $\mathrm{Na}_{2} \mathrm{~B}_{4} \mathrm{O}_{7}$ solution with $200 \mathrm{~g} / \mathrm{L} \mathrm{NaOH}$ solution tune to the required value in $\mathrm{pH}$ meter; Tween-80:20 g/L. 1-(4-Antipyrine)-3-(3-nitroaniline)triazene 
(ANTA) solution: weighed $0.25 \mathrm{~g}$ colour reagent, dissolved with ethanol then moved into $250 \mathrm{~mL}$ volumetric flask, diluted with ethanol to scale and shake, its concentration was $2.7 \times$ $10^{-3} \mathrm{~mol} / \mathrm{L}$.

Reagents all above were of analytical grade, water used in the test was double distilled water.

Diazotization and coupling reaction: According to method as reported in reference ${ }^{11}$, obtained clarified orangered diazonium salt solution after diazotization. Then weighed $0.680 \mathrm{~g}$ (0.01 mol) 3-nitroaniline dissolved in $35 \mathrm{~mL}$ ethanol and slowly dropped into the diazonium salt solution, with saturated sodium carbonate solution to adjust $\mathrm{pH}$ value of 5-6, with precipitates formation. Removed ice bath, put it aside at room temperature overnight, filtration, washed and precipitated with water and $50 \%$ ethanol, respectively, dried in low temperature, obtained reddish-brown precipitate.

The main reaction equation as Fig. 1:

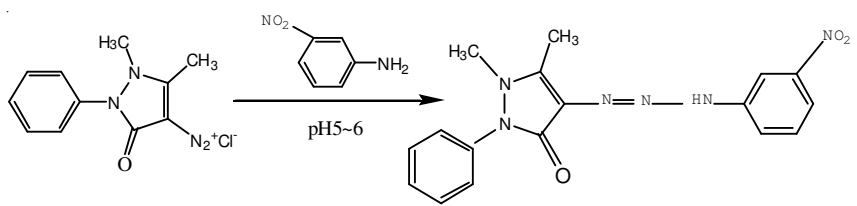

Fig. 1. Main coupling reaction equations

Purification and identification dissolved the crude product in an appropriate amount of ethanol-water, recrystallized 2 times and obtained a red-brown product, its melting point is $145^{\circ} \mathrm{C}$. Element analysis results to the experimental value (theoretical value) is expressed as: $\mathrm{C} 67.23 \%(67.11 \%) ; \mathrm{H}$ $5.17 \%(5.26 \%)$; N $27.65 \%(27.63 \%)$.

IR spectra data of product (KBr tablet, $\mathrm{cm}^{-1}$ ) (Fig. 2): 3420 $\mathrm{cm}^{-1}$ is the stretching vibration absorption peak for N-H; 3168 $\mathrm{cm}^{-1}$ is the stretching vibration absorption peak for $\mathrm{C}-\mathrm{H}$ in benzene ring; $1658 \mathrm{~cm}^{-1}$ is the asymmetric stretching vibration absorption peak for $\mathrm{C}=\mathrm{O} ; 1526,1491$ and $1451 \mathrm{~cm}^{-1}$ are stretching vibration absorption peak for the benzene ring framework (i.e., $1526 \mathrm{~cm}^{-1}$ is the stretching vibration absorption peak for $\mathrm{C}=\mathrm{C} ; 1350 \mathrm{~cm}^{-1}$ is the stretching vibration absorption peak for $\mathrm{N}=\mathrm{N}) ; 1126 \mathrm{~cm}^{-1}$ is the stretching vibration absorption peak for the $\mathrm{C}-\mathrm{NO}_{2}$.

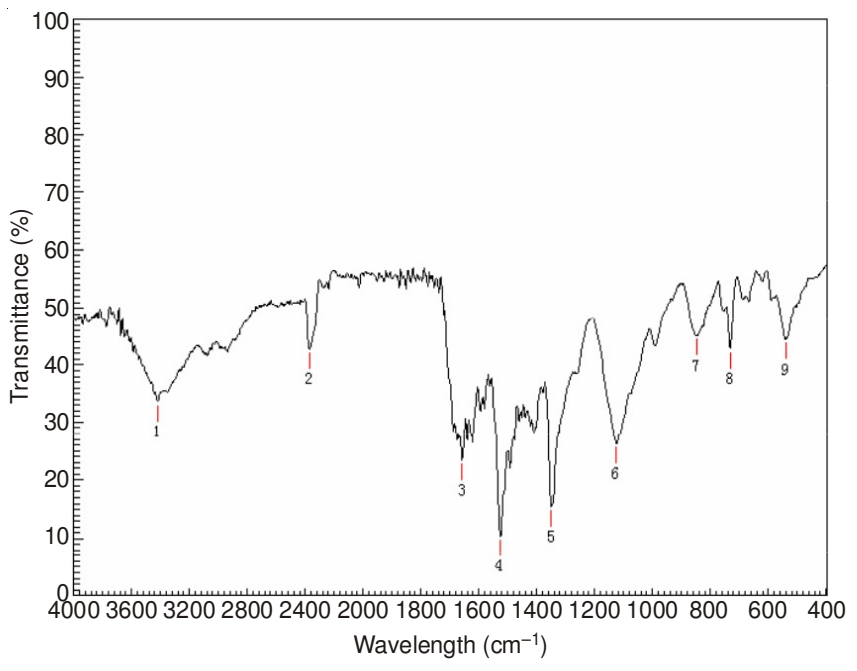

Fig. 2. IR spectra of ANTA
Experimental methods: Pipette $0.5 \mathrm{~mL} 10.0 \mu \mathrm{g} / \mathrm{mL}$ $\mathrm{Hg}$ (II) standard working solution in $10 \mathrm{~mL}$ flask, followed by adding $1.6 \mathrm{~mL} 20 \mathrm{~g} / \mathrm{L}$ of Tween-80 solution, $1.3 \mathrm{~mL}$ of $\mathrm{pH}$ $10.0 \mathrm{Na}_{2} \mathrm{~B}_{4} \mathrm{O}_{7}-\mathrm{NaOH}$ buffer solution, $1.6 \mathrm{~mL} 2.7 \times 10^{-3} \mathrm{~mol} / \mathrm{L}$ 1-(4-antipyrine)-3-(3-nitroaniline)triazene, diluted to scale and shake. After $10 \mathrm{~min}$, measure the absorbance of the solution with a $1 \mathrm{~cm}$ cuvette at $495 \mathrm{~nm}$ and take reagent blank as reference.

\section{RESULTS AND DISCUSSION}

Absorption curve: Determined adsorption spectra curves of reagent and complex at different wavelengths in experimental methods (Fig. 3). Maximum absorption wavelength of the reagent blank was $370 \mathrm{~nm}$, maximum absorption wavelength of the binary system was $480 \mathrm{~nm}$, in the Tween-80 ternary system the maximum absorption wavelength was 495 $\mathrm{nm}$, compared with reagent blank, contrast ratio reaches 118 $\mathrm{nm}$, compared with binary system, the red shift was $8 \mathrm{~nm}$, the sensitivity was significantly higher, so chose $495 \mathrm{~nm}$ as detecting wavelength.

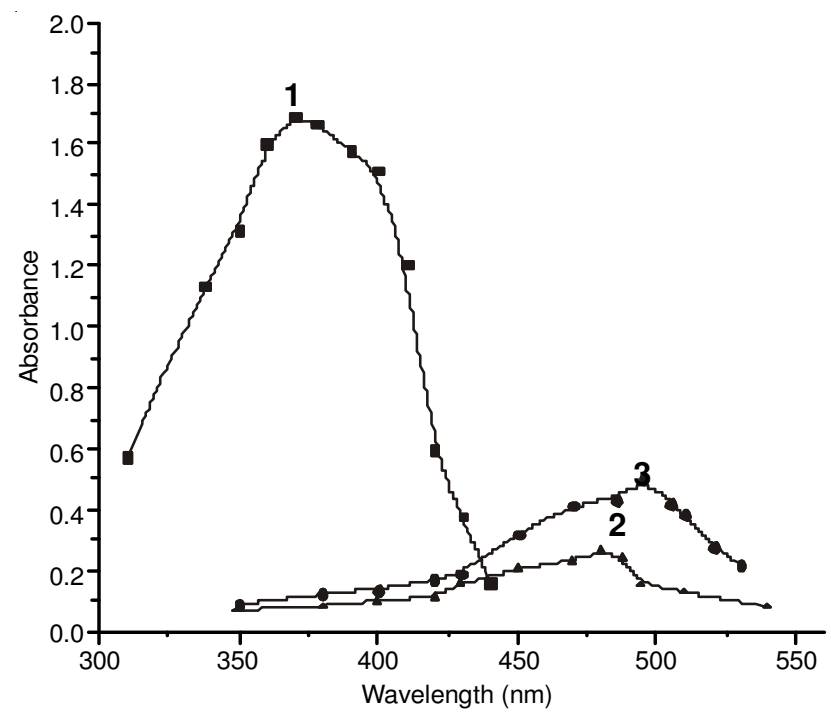

Fig. 3. Absorption spectra. 1. Reagent blank/water; 2. 5.0 $\mu \mathrm{g} \mathrm{Hg}$ (II)-ANTA/ reagent blank; 3. $5.0 \mu \mathrm{g} \mathrm{Hg}$ (II)-Tween-80- ANTA/reagent blank (C $\mathrm{ASTA}=2.5 \times 10^{-4} \mathrm{~mol} / \mathrm{L}$ )

Effect of system acidity: We have tested the effect of $\mathrm{HCl}, \mathrm{H}_{2} \mathrm{SO}_{4}, \mathrm{H}_{3} \mathrm{PO}_{4}, \mathrm{AcOH}-\mathrm{NaOAc}$, HCI-KHP, $\mathrm{Na}_{2} \mathrm{~B}_{4} \mathrm{O}_{7}-\mathrm{HCl}$, $\mathrm{Na}_{2} \mathrm{CO}_{3}-\mathrm{NaHCO}_{3}, \mathrm{NH}_{3} \cdot \mathrm{H}_{2} \mathrm{O}-\mathrm{NH}_{4} \mathrm{Cl}, \mathrm{Na}_{2} \mathrm{~B}_{4} \mathrm{O}_{7}-\mathrm{NaOH}, \mathrm{NaOH}$, $\mathrm{H}_{3} \mathrm{BO}_{3}-\mathrm{NaOH}$ and other media on system, $\mathrm{Na}_{2} \mathrm{~B}_{4} \mathrm{O}_{7}-\mathrm{NaOH}$ solution is the most appropriate. When the solution $\mathrm{pH}$ in the range of 9.6-10.3, the system absorbance reached the maximum and stable, so chose $\mathrm{Na}_{2} \mathrm{~B}_{4} \mathrm{O}_{7}-\mathrm{NaOH}$ solution of $\mathrm{pH} 10$ to control acidity. When the amount is in the range of 1.0-1.6 $\mathrm{mL}$, all can control the acidity, so selected $1.3 \mathrm{~mL}$ solution.

Influence of the colour reagent dosage: When the colour reagent dosage in the range of 1.2-3.8 $\mathrm{mL}$, system absorbance reached the maximum and stable, so chose $1.5 \mathrm{~mL}$.

Surfactant types and the choice of the amount: After investigated different types of surfactants on the impact of the colour system, results showed that: cationic, anionic and nonionic surfactant all have good solubilization on system, but nonionic surfactants has the most significant effect on the sensitizing of system. In this study, it was found that Tween-80 
TABLE-1

DETERMINATION RESULTS OF MERCURY(II) IN THE LEAD-ZINC ORE SAMPLES ( $\mathrm{n}=6$ )

\begin{tabular}{cccccccc}
\hline Sample & $\begin{array}{c}\text { By AAS } \\
(\mu \mathrm{g} / \mathrm{g})\end{array}$ & $\begin{array}{c}\text { This method } \\
\text { average }(\mu \mathrm{g} / \mathrm{g})\end{array}$ & $\begin{array}{c}\text { RSD } \\
(\%)\end{array}$ & $\begin{array}{c}\text { Added } \mathrm{Hg}(\mathrm{II}) \\
(\mu \mathrm{g} / \mathrm{g})\end{array}$ & Recovery Hg(II) $(\%)$ & $\begin{array}{c}\text { Average } \\
\text { recovery }(\%)\end{array}$ \\
\hline Lead-zinc mine type 1 & 0.64 & 0.68 & 4.2 & 10 & $102.5,102.7,103.1,103.4,103.7,103.8$ & 103.2 \\
Lead-zinc mine type 2 & 0.71 & 0.75 & 4.6 & 10 & $102.3,102.6,102.9,103.1,103.3,103.5$ & 103.0 \\
\hline
\end{tabular}

solution has better stability, solubility and sensitivity. The amount of it was in the range of 1.4-1.9 mL, absorbance was the maximum and stability, so chose $1.6 \mathrm{~mL}$.

Influence of reagent adding order and colour reaction time and the stability of complex various adding order of reagents will affect the colour reaction. The results showed that the adding order of reagents according to the experimental method was the best; the system could finish colour reaction completely in $10 \mathrm{~min}$ at room temperature and stay stability for $6 \mathrm{~h}$.

Determination of complex components: Molar ratio method and continuous change method determined the composition of complex was $\mathrm{n}[\mathrm{Hg}(\mathrm{II})]: \mathrm{n}(\mathrm{ANTA})=1: 2$.

Influence of coexisting ions: Determined $5 \mu \mathrm{g} \mathrm{Hg}(\mathrm{II})$ according to experimental method, the relative error $\leq \pm 5 \%$, the allowed amount of coexisting ions (calculate in $\mu \mathrm{g}$ ): $\mathrm{K}^{+}$ (12000), $\mathrm{Na}^{+}$(10000), $\mathrm{Mg}^{2+}$ (1800), $\mathrm{Ba}^{2+}$ (1500), $\mathrm{Fe}^{2+}$ (700), $\mathrm{Ca}^{2+}$ (600), Ti(IV) (80), Os(III), $\mathrm{Ag}^{+}$(50), $\mathrm{Al}(\mathrm{III})$ (45), In(III) (40), $\mathrm{Mn}^{2+}$ (30), $\mathrm{Pt}^{2+}, \mathrm{Ge}^{2+}, \mathrm{Au}(\mathrm{III})$ (25), V(V) (20), Zr (IV), $\mathrm{Pd}^{2+}$ (15), Cr(VI) (12), Ru(III), W(III), Mo(VI) (10), Sb(III), $\mathrm{Rh}$ (III) (8), $\mathrm{Cd}^{2+}(5), \mathrm{Zn}^{2+}, \mathrm{Cr}$ (III) (3.5), $\mathrm{Ni}^{2+}$ (2), $\mathrm{Pb}^{2+}, \mathrm{Sn}$ (IV) (1), $\mathrm{Bi}(\mathrm{III}), \mathrm{Co}^{2+}(0.5)$. Common $\mathrm{SO}_{4}{ }^{2-}, \mathrm{PO}_{4}{ }^{3-}, \mathrm{NO}_{3}{ }^{-}, \mathrm{OAc}^{-}, \mathrm{Br}^{-}$ and other ions do not interfere with the determination, sulfosalicylic acid (35000), ethylene diamine, tartrate (30000). In the reaction system by adding $0.5 \mathrm{~mL}$ mixed masking agent $10 \mathrm{~g} / \mathrm{L}$ ammonium fluoride-20 g/L sulfosalicylic acid $-10 \mathrm{~g} / \mathrm{L}$ ethylenediamine can make the following ions $(\mu \mathrm{g})$ do not interfere with the determination of $\mathrm{Hg}(\mathrm{II})$ in system: $\mathrm{Cu}^{2+}(30)$, $\mathrm{Cd}^{2+}(25), \mathrm{Co}^{2+}, \mathrm{Ni}^{2+}(20)$. If the system is of serious interference, use thiol dextran gel (SDG) column for adsorption according to the method in literature ${ }^{12}$, the common $\mathrm{Mn}^{2+}, \mathrm{Ca}^{2+}$, $\mathrm{Mg}^{2+}, \mathrm{Pb}^{2+}, \mathrm{Zn}^{2+}, \mathrm{Co}^{2+}, \mathrm{Ni}^{2+}, \mathrm{Al}^{3+}$ and other ions are not adsorbed and $\mathrm{Cu}^{2+}, \mathrm{Hg}^{2+}, \mathrm{Sn}^{4+}$ were quantitatively adsorbed at the same time, with $4 \mathrm{~mol} / \mathrm{L}$ of $\mathrm{HCl}$ for elution, then $\mathrm{Sn}^{4+}$ was washed off, after throwing away the elution then elute $\mathrm{Cu}^{2+}$, with 6 $\mathrm{mol} / \mathrm{L} \mathrm{HCl}$ at this time but $\mathrm{Hg}^{2+}$ still remain in the adsorption column and then elute $\mathrm{Hg}^{2+}$ remaining in adsorption column with $8 \mathrm{~mol} / \mathrm{L} \mathrm{HCl}-0.1 \mathrm{~mol} / \mathrm{L} \mathrm{NaCl}$ solution to determine, it greatly improved the selectivity of the method.

Calibration curve and sensitivity: Prepare a series of $10 \mathrm{~mL}$ colourimetric tubes, followed by adding a certain amount of mercury(II) standard working solution for colour reaction determination, determined by experimental methods,
Beer's law was obeyed in the range of $0.32-10 \mu \mathrm{g} / 10 \mathrm{~mL}$ for $\mathrm{Hg}(\mathrm{II})$, linear regression equation: $\mathrm{A}=0.1874 \rho+0.0010$, correlation coefficient $r=0.9998$, in the prepared experimental condition, measured the apparent molar absorption coefficient $\varepsilon$ was $3.8 \times 10^{5} \mathrm{~L} \mathrm{~mol}^{-1} \mathrm{~cm}^{-1}$, the detection limit was $0.10 \mathrm{mg} / \mathrm{L}$.

Sample analysis: Accurately weighed $0.5 \mathrm{~g}$ sample and turned into the horizontal double-tube through dry, longnecked small funnel, added $1 \mathrm{~g}$ of reduced iron powder and after mixed, heated slowly for 1-2 min on the torch with tiny fire. After dried off water, continued to heat up for 2-3 min and then took the end of the ball adjacent to the glass tube softened in the high temperature, sealed tube end after pulled the end ball through clamp, added $5 \mathrm{~mL}$ concentrated nitric acid after cooling tube, heated for $0.5 \mathrm{~h}$ in water bath pan, cooled, moved the solution within the tube into a small $50 \mathrm{~mL}$ beaker. Washed glass tube with water, added $1 \mathrm{~mL}(1+3)$ sulphuric acid, heated slowly at low temperature on heating plate until nitric acid completely vapour and disappeared (left beaker volume 1-2 $\mathrm{mL}$ ), moved the beaker solution into 50 $\mathrm{mL}$ volumetric flask. According to the reported method ${ }^{13}$, through sulfhydryl dextran gel (SDG) adsorption column, diluted to the mark with water, mixed. Took a certain amount of sample solution determined mercury(II) content in experimental method, results as shown in Table-1.

\section{REFERENCES}

1. S.V. Romanenko and L.N. Larina, J. Electroanal. Chem., 583, 155 (2005).

2. B. Vallant, R. Kadnar and W. Goessler, J. Anal. At. Spectrom., 22, 322 (2007).

3. X.P. Zhu and S.D. Alexandratos, Microchem. J., 86, 37 (2007).

4. J.C.A de Wuilloud, R.G. Wuilloud, M.F. Silva, R.A. Olsina and L.D. Martinez, Spectrochim. Acta B, 57, 365 (2002).

5. R.B. Voegborlo and H. Akagi, Food Chem., 100, 853 (2007).

6. R.H. Yang, K. Li, K. Wang, F. Liu, N. Li and F.L. Zhao, Anal. Chim. Acta, 469, 265 (2002).

7. Y.-M. Zhou, L.-Q. Li, G.-F. Wang and G. Zhang, Metallurg. Anal., 20, 38 (2000).

8. K. Kilian and K. Pyrzynska, Talanta, 60, 669 (2003).

9. A. Sunil and S.J. Rao, Res. J. Chem. Sci., 2, 31 (2012).

10. Hai-Qing Wang, Zhi-Jin Yue, Yong-Wen Liu et al., J. Spectrometry Lab., 5, 22 (2005).

11. X. Zhao, P. Liu and Z.-T. Ding, Gold, 9, 28 (2007).

12. Y.-H. Li, J.-Y. Sun and W.-B. Chen, Metallurgical Anal., 5, 14 (2004). 